\title{
Spending Time and Money within the Household
}

\author{
Martin Browning \\ CAM, \\ Department of Economics, \\ University of Copenhagen
}

Mette Gørtz CAM, Department of Economics, University of Copenhagen

January 2006

\begin{abstract}
We consider theoretically and empirically the allocation of time and money within the household. The novelty of our empirical work is that we have a survey which provides information on both time use and the allocation of some goods within the household, for the same households. Thus we can consider whether a partner who enjoys more leisure also receives more consumption, which looks like the outcome of 'power' within the household, or receives less consumption, which looks like differing tastes across households.
\end{abstract}

Keywords: Intra-household allocation, household production

JEL classifications: C3, D1, J1, J2

\section{Introduction}

The most consistent finding regarding time use across countries and over time is that, on average, married men do more market work and less housework than married women. It has also been found that, on average, married men and women enjoy much the same leisure. ${ }^{1}$ These averages, however, mask

\footnotetext{
${ }^{1}$ The major exception to this is Italy.
} 
very marked heterogeneity in time use within individual households. Thus we find some households in which one partner does a good deal more work (in the market and in the home) than the other partner and enjoys less leisure. There are a number of possible rationale for this. First, there may be heterogeneity in the tastes for work (relative to the output from the work) within the household. Second, wages and/or productivity in home production may vary, which would induce differences in the leisure taken. Finally, 'power' may be distributed unevenly within the household and the 'low power' individual may be required to work more. Data on time use alone do not suffice to identify the relative importance of these three factors. To identify this, we need to observe other outcomes within the household. The distribution of material welfare within the household depends on two elements: individual time use and the allocation of expenditures. Time use surveys give a good picture of the distribution of time to market work, housework, leisure and personal care between partners but do not have comparable information on expenditures. This means that we cannot convincingly make the mapping from time use to welfare.

As an example that we shall often return to below, consider a household comprising of a married couple in which the wife works more (in the home and in the market) as compared to other women with similar characteristics, wage of husband and wife and household financial situation. To make the link to her material welfare relative to other women, we need to know what is happening to the distribution of goods within the household. If we would observe that she receives more goods than we would predict, then we could attribute the observation to her having a high taste for goods relative to leisure. $^{2}$ If, on the other hand, we observed that she also receives less goods then it looks as though she lacks 'power' within the household and that the distribution of material well-being within the household is skewed towards the husband. Clearly, we need to observe both sets of outcomes (the allocation of time and money) to calculate the intra-household distribution of material well-being and its determinants.

The traditional focus of welfare analysis has been on the distribution of material well-being across households - the inter-household distribution. The household has been viewed as one unit, and it has implicitly been assumed that household members do not have conflicting interests. This description is usually referred to as the 'unitary' model. In the past two decades there

\footnotetext{
${ }^{2}$ We shall formalize this in the theory section below.
} 
has been a number of analyses of the situation in which household members have conflicting objectives and a growing interest regarding the distribution of material well-being within the household; that is, the intra-household distribution of material well-being. A number of different approaches have been suggested; see Browning, Chiappori and Lechene (2005) for references. One particularly popular approach is to assume that, however decisions are made, the outcome is always Pareto-efficient, see Chiappori (1988), Apps and Rees (1988) and Browning and Chiappori (1998). This assumption is central in the 'collective model' where the distribution of 'power' in the household contributes to determining intra-household distribution. This paper explores and compares the implications of adopting a 'unitary' versus a 'collective' framework to describe the allocation of well-being.

The intra-household allocation of expenditures has been the principal focus in a number of theoretical and empirical studies during the last two decades, (see, for example, Browning et al (1994), Lundberg et al (1996) and Phipps and Burton (1998)). Other studies have dealt with the intrahousehold allocation of time, see Chiappori (1992) and (1997) and Apps and Rees (1996) and (1997). Apps and Rees address the question of whether household members exchange time for consumption and stress the need for data on the simultaneous allocation of time and consumption within households.

Below we present an empirical analysis based on a survey of Danish households that was specifically designed for the research reported in this paper. The survey is unique in the sense that it collects both time use data and information on the intra-household allocation of goods for the same households. As far as we are aware, this is the first time that data on time use and the allocation of goods within the household have been available in the same survey. This gives us the opportunity to present a much fuller picture of the distribution of material well-being within the household than has been possible in the past. In the next section we give a description of our data collection and some descriptive results for time use and individual expenditures. In section 3 we present a simple theoretical model designed to isolate the effects discussed above. We choose a simple parameterisation for two reasons. First, it allows us to discuss clearly what we think are the main theoretical issues without excessive concern for perverse effects due to strong substitutability or complementarity between the consumption of different goods and time use. Second, our parameterisation leads to a structural model that yields linear reduced forms that can be taken to the data. Also in section 
3, we discuss how to account for observed and unobserved heterogeneity and present our identification scheme. An important aspect of our identification scheme is that we can allow that wages are endogenous through their correlation with unobservable tastes for work. In section 4 we present an empirical structural analysis of the data on time use and the allocation of goods within the household.

\section{The Danish Time Use Survey}

\subsection{Background}

Our data are from the Danish Time Use Survey for 2001 (DTUS). This survey provides detailed information on time use for more than 2700 Danish individuals in 2001 of whom about 1700 lived with a partner. The DTUS complies with methodologies developed at the EU level for conducting time use surveys; see Bonke (2005) for a detailed description. For married and cohabiting respondents, the partner in the household was also asked to participate in the survey. We have two sources of information on time use. First, each respondent filled in a diary stating their activities at a detailed level every 15 minutes in two 24-hour periods, one a week-day and the other a weekend day. The second source is from the questionnaire in which respondents were asked about their 'usual' time use.

A unique feature of the data collection is that respondents were also asked about their and their partner's expenditures on three categories of goods, bought for their own consumption. The details of the expenditure module are given below. The module was designed by Jens Bonke and Martin Browning in collaboration with Denmarks Statistics who ran the survey. Browning, Crossley and Weber (2003) present a discussion of the pros and cons of using information on 'usual' expenditures from general purpose surveys. The broad conclusion from their analysis is that although survey measures are noisy as compared to diary measures, they do contain a useful signal. The questionnaire also asked about personal and household characteristics as well as about the usage of domestic appliances and individual perception of their economic situation.

Finally, these survey data were linked to register (administrative) infor-

mation from Denmarks Statistics on the respondent and partner, giving access to further personal and household information and information on hous- 
ing. Particularly important in this respect is that the register data contains a wage measure for employed individuals that is constructed independently of the time use collected in the survey so that we do not have the familiar division bias when considering time use and wages. The DTUS is unique in having information on time use, individual expenditures and wages for the same household.

\subsection{Time use}

As well as keeping a time diary, respondents were asked about the time they normally spend on housework and in the labour market in a typical week. Housework time is specified to include normal housework such as cleaning, laundry, shopping, cooking etc. and also gardening, repairs, other do-ityourself work and child care. ${ }^{3}$ Market work time includes commuting. In general, it is observed that surveys asking about normal time use have a smaller variance, but perhaps a more imprecise mean of time use, see Juster and Stafford (1991). Diary information gives more precise means, but the variance is larger, especially when including time for home repairs etc. We have chosen to use normal time use rather than the diary information to avoid the very serious infrequency problems in the latter. In the Appendix we provide a comparison of the diary records and the normal times reported.

Table 1 shows the time usage of couples, broken down by the work status of the two partners. We define full-time market work to be at least 30 'normal' hours per week, including commuting time. Thus a respondent may be unemployed in the survey week and still report more than 30 hours per week of market work. Part-time work is not very prevalent in Denmark so that 'not full-time' generally means 'out of the labour force' (particularly for men). The 'neither full-time' group is mostly made up of older, presumably retired, couples. Table 1 shows familiar patterns with men doing less housework than women who have the same work status, but with leisures being roughly equal (in mean) for those with the same status. Being full-time employed has a dramatic effect on mean leisure with about 30 hours per week less for women and 35 hours less for men. For our purposes, a particularly important feature of the time uses shown is their wide within category dispersion, as shown by the standard deviations.

\footnotetext{
${ }^{3}$ As always the classification of child care as housework is contentious. No one seriously argues that it cannot also be an important leisure activity. Since respondents were only asked one question on housework, we cannot break out child care separately.
} 
Figure 1 shows the details of leisure for the 'both full-time' group. The left hand panels show the levels for wives and husbands. ${ }^{4}$. As can be seen there is considerable dispersion. The top right hand panel shows the wife's relative leisure, defined as the wife's leisure relative to the husband's leisure. The median and mean are 0.98 and 0.99 respectively but about $10 \%$ of couples have a leisure relative below 0.8 and $7 \%$ have above 1.25 . The scatter plot in the bottom right panel indicates a positive correlation between the two leisures with a slope less than unity (the OLS value is 0.51 with a t-value of 14.9). There are many candidate explanations for this positive correlation, including assortative mating on wages (so that two partners with high wages will both take less leisure), assortative mating on preferences for leisure or complementaries in leisure.

\begin{tabular}{|l|c|c|c|c|c|c|}
\hline & \multicolumn{3}{|c|}{ Females } & \multicolumn{3}{c|}{ Males } \\
\hline \hline Full-time & $m$ & $h$ & $l$ & $m$ & $h$ & $l$ \\
\hline \hline Both & 40.5 & 15.7 & 55.8 & 44.7 & 10.9 & 56.4 \\
$(\#=813)$ & $(6.0)$ & $(8.7)$ & $(10.3)$ & $(9.1)$ & $(7.6)$ & $(11.1)$ \\
\hline Wife & 40.2 & 13.1 & 58.6 & 2.0 & 13.1 & 96.3 \\
$(\#=114)$ & $(4.9)$ & $(8.1)$ & $(10.1)$ & $(6.8)$ & $(8.1)$ & $(12.2)$ \\
\hline Husband & 5.7 & 18.1 & 88.2 & 45.1 & 9.3 & 57.5 \\
$(\#=311)$ & $(10.6)$ & $(11.9)$ & $(16.6)$ & $(10.5)$ & $(6.7)$ & $(12.2)$ \\
\hline Neither & 1.1 & 18.9 & 91.9 & 0.7 & 13.0 & 98.2 \\
$(\#=284)$ & $(5.2)$ & $(11.7)$ & $(12.9)$ & $(3.9)$ & $(10.9)$ & $(11.2)$ \\
\hline \hline$m, h$ and $l$ are market hours, housework hours \\
and leisure hours per week. Sd's in brackets. \\
\hline Note: $m+h+l+42=168$ \\
\hline
\end{tabular}

Table 1: Time use of wives and husbands

In the following, we analyse only the sample of households in which both husband and wife work full-time in the labour market. This is to allow us to focus on the role of relative wages on the intrahousehold allocation of time and money. The analysis of the disparity in leisures between partners who do not have the same full-time status is left for future work. The load of housework for full-time couples (which we define to include child care) naturally depends on the number and ages of children within the household. Table 2

\footnotetext{
${ }^{4}$ With values below 40 set to 40 for the sake of presentation.
} 

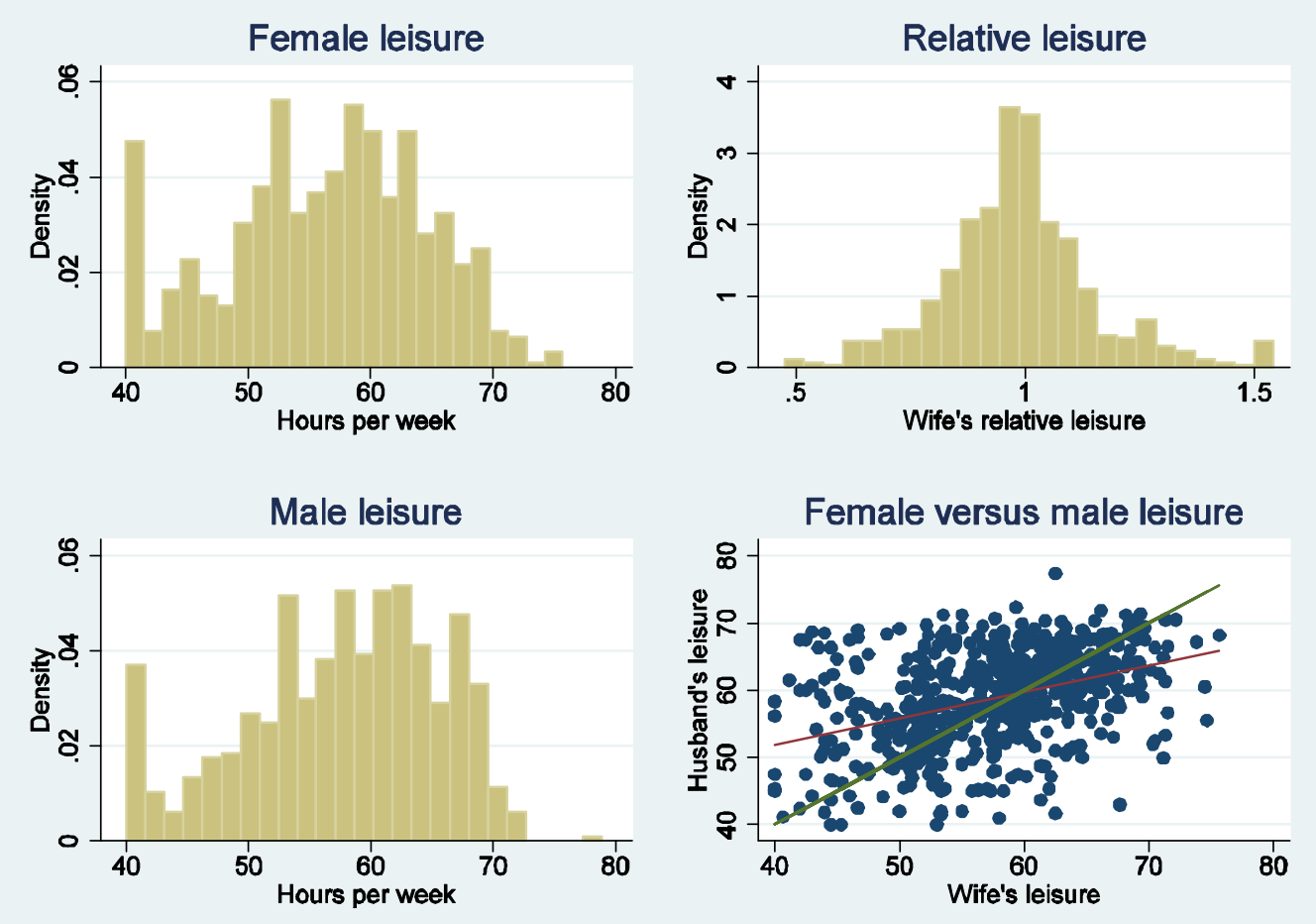

Figure 1: Leisure for husband and wife.

presents time use broken down by child status. This table indicates that although children have some effect (in the expected directions) the differences are not large, once we condition on both partners being in full-time work. In particular, parents do not have drastically lower leisures which suggests that they may even have more leisure is we re-categorise some time spent with children as leisure.

\subsection{Personal expenditures}

As mentioned above, the primary objective of the DTUS was to collect information on time use and we could only collect limited information on personal expenditures. The following questions were asked of the respondent:

'When you think of your own personal expenditures, how large do you 


\begin{tabular}{|l|c|c|c|c|c|c|}
\hline & \multicolumn{3}{|c|}{ Females } & \multicolumn{3}{c|}{ Males } \\
\hline \hline$\#$ children & $m$ & $h$ & $l$ & $m$ & $h$ & $l$ \\
\hline \hline 0 & 41.0 & 13.5 & 57.5 & 44.5 & 9.4 & 58.0 \\
$(\#=357)$ & $(6.3)$ & $(7.5)$ & $(9.9)$ & $(10.1)$ & $(6.5)$ & $(11.4)$ \\
\hline 1 & 40.7 & 15.1 & 56.2 & 43.7 & 10.7 & 57.6 \\
$(\#=175)$ & $(6.3)$ & $(7.5)$ & $(9.3)$ & $(7.0)$ & $(7.5)$ & $(8.8)$ \\
\hline $2+$ & 39.9 & 18.8 & 53.3 & 45.5 & 13.0 & 53.5 \\
$(\#=281)$ & $(5.4)$ & $(9.8)$ & $(10.9)$ & $(8.8)$ & $(8.5)$ & $(11.5)$ \\
\hline \multicolumn{2}{|l|}{ Notes: see Table 1 }
\end{tabular}

Table 2: Time use by child category

estimate it normally is on the following items during one month':

- 'Clothing and shoes'

- 'Leisure activities, hobbies etc.'

- 'Other personal consumption'

The respondent was then asked the same questions for their spouse/cohabitant. It is very rare to have survey information on expenditures for individuals within the household and questions can be raised about the validity of the information obtained in this way. Fortunately, in Denmark we have a reliable survey of within household allocations from the Danish Household Expenditure Survey (DHES) which can be used to check the validity of our responses. The DHES is a conventional diary based survey of expenditures with the unconventional feature that respondents keeping an expenditure diary record who the item was bought for ('her', 'him', 'the household', 'children' and 'other'). ${ }^{5}$ Since the DHES has very detailed categories for goods we can construct aggregates that correspond to our three aggregates. Comparing the information in our survey (the DTUS) and the DHES we find that for 'clothing' and 'recreation', the expenditure shares are very close to the corresponding groups from DHES. For 'other personal consumption', there is some divergence, but this may very well be attributed to differences in the definition of this group. In future work we shall combine the information from both surveys but this raises statistical issues (mainly dealing with the

\footnotetext{
${ }^{5}$ This is also due to a data initiative of Bonke and Browning.
} 
infrequency in the DHES data) that would take us too far from the analysis presented here.

Many households did not give consumption information and some had missing wage information in the administrative data. In the end we have 615 households in which both partners are in full-time work and for which we have all of the necessary time use, expenditure, wage and demographic information. Appendix A.5 gives details of the sample selection. Figure 2 shows the distribution of the wife's relative expenditure (with values above 3 set to that value) for that sample. As can be seen the mode is close to unity and, indeed, many households report exactly the same expenditures on the three goods for husband and wife. This clearly indicates some reporting error but informal analysis (which assumes that the 'same value' reports are due to rounding) suggests that this does not lead to significant bias. In the data $20 \%$ of households have an expenditure relative above 1.5 and $18 \%$ have a value below $1 / 1.5$.

Figure 3 shows the scatter plot of relative leisures against relative expenditures for our sample. This is at the heart of our research question. If within household heterogeneity dominates then, conditional on relative wages, the two relative measures should be negatively correlated. If, on the other hand, power dominates then the correlation should be positive. The scatter diagram shows a mild positive association (the OLS value is 0.029 with a t-value of 2.35) but this does not take account of differences in relative wages. To do that we need a structural model.

\section{Theory}

\subsection{Allocation within the household}

In this section we develop a simple model of the allocation of time and money within the household. We consider a two person household with $A$ being 'she' and $B$ being 'he'. The two members of the household sell labour on a labour market at fixed wages and they buy private goods which are distributed between the two partners. The members of the household also engage in housework which produces a public good that is consumed jointly. Table 3 presents our notation and the following equations give the constraints the 


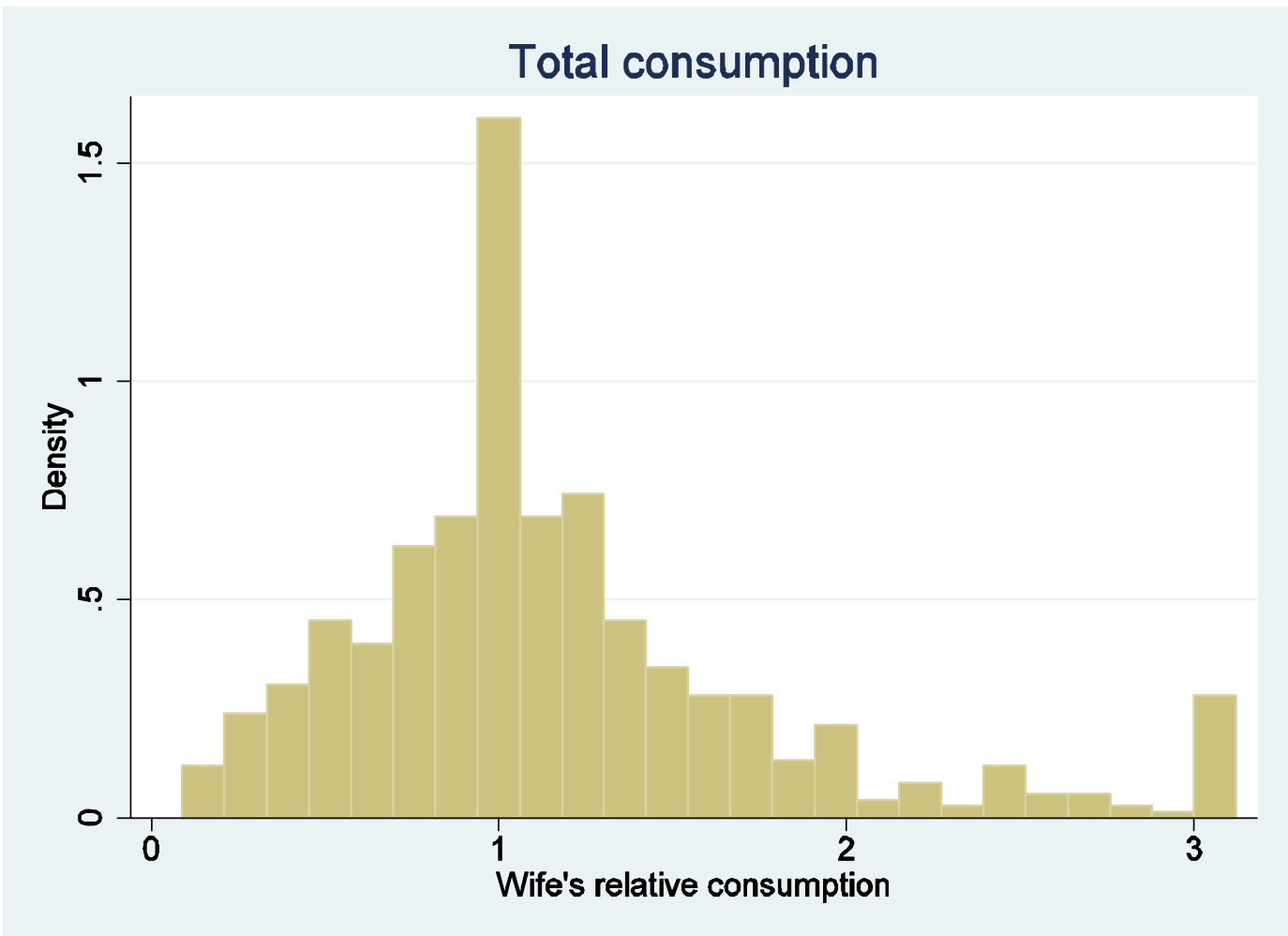

Figure 2: Wife's expenditure relative to husband's. 


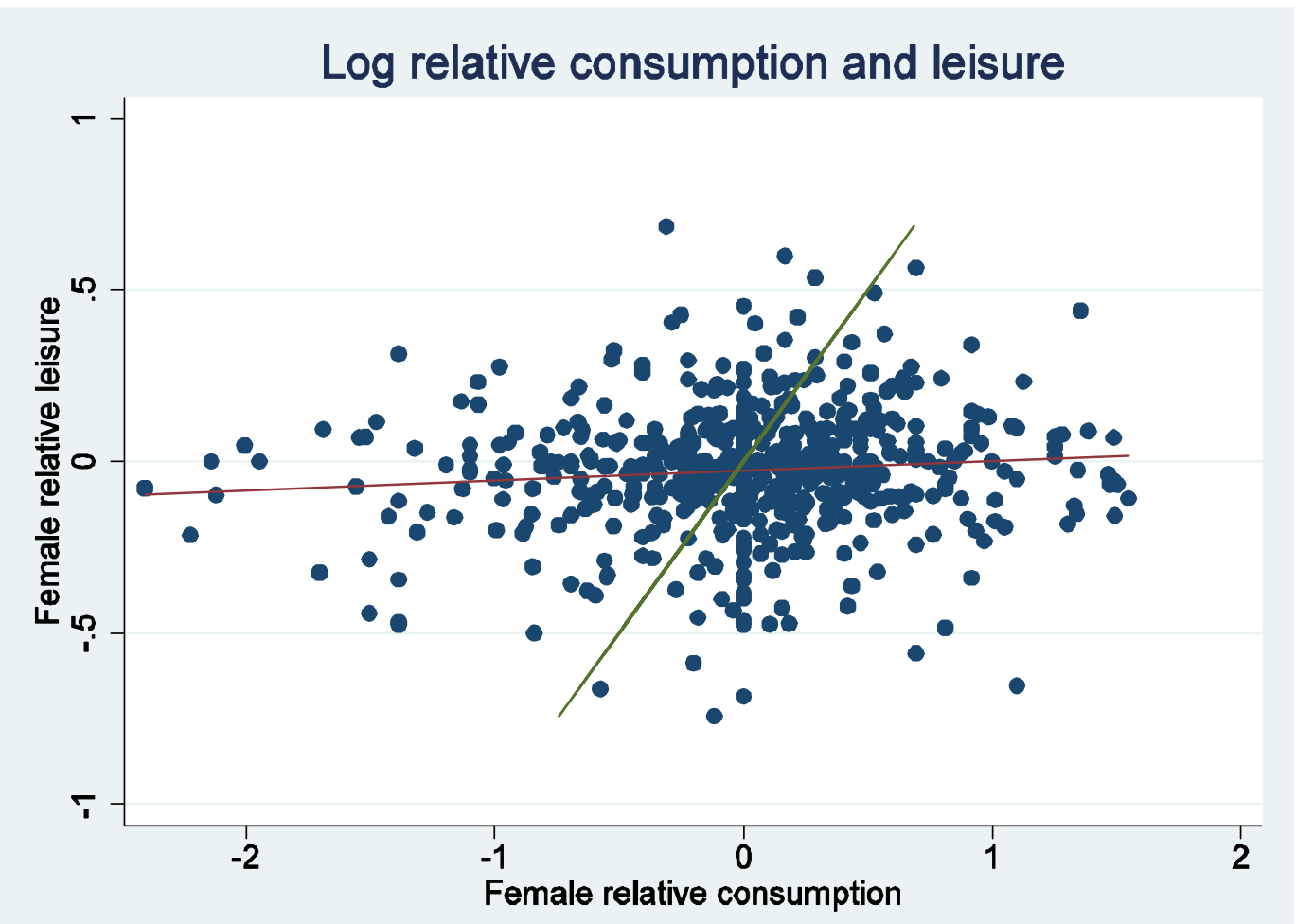

Figure 3: Expenditure and leisure 
household faces.

$$
\begin{aligned}
x_{H}+x_{A}+x_{B} & =w_{A} m_{A}+w_{B} m_{B}+y \\
l_{A}+h_{A}+m_{A} & =T \\
l_{B}+h_{B}+m_{B} & =T \\
Q & =F\left(h_{A}, h_{B}, x_{H}\right)
\end{aligned}
$$

In these constraints we assume that the household public good, $Q$, is produced with inputs of time and physical inputs for household production (equation (4)). We assume that $F($.$) is smooth with F_{A}, F_{B}$ and $F_{x}$ (the partials with respect to the respective levels of housework and money inputs) all positive.

\begin{tabular}{|l|l|}
\hline$x_{A}$ & $A$ 's total expenditure on private goods \\
\hline$x_{H}$ & Expenditure on household production \\
\hline$Q$ & Household public good \\
\hline$l_{A}$ & $A$ 's leisure time \\
\hline$h_{A}$ & $A$ 's housework time \\
\hline$m_{A}$ & $A$ 's market work \\
\hline$w_{A}$ & $A$ 's wage \\
\hline$y$ & Household 'other income' \\
\hline \hline $\begin{array}{l}\text { We adopt the convention of denoting relative values } \\
\text { by the notation without subscripts. For example: }\end{array}$ \\
\hline$x$ & $A$ 's relative expenditure $=x_{A} / x_{B}$ \\
\hline$w$ & $A$ 's relative wage $=w_{A} / w_{B}$ \\
\hline
\end{tabular}

Table 3: Notation

Given the constraints the household faces, we have to model how the two people make decisions over the ten choice variables:

$$
\left(x_{H}, x_{A}, x_{B}, Q, l_{A}, l_{B}, h_{A}, h_{B}, m_{A}, m_{B}\right)
$$

We assume that each person has private preferences over their own goods, represented by the felicity function:

$$
\begin{aligned}
& u^{A}=u^{A}\left(x_{A}, Q, l_{A}\right) \\
& u^{B}=u^{B}\left(x_{B}, Q, l_{B}\right)
\end{aligned}
$$


This formulation explicitly assumes that there are no externalities so that, for example, A's valuation of her leisure is independent of her husband's leisure. The 'no externalities' assumption is undoubtedly unrealistic but is widely used since it allows us to infer individual welfares from potential observables. We will return to the discussion on complementarity in leisures below. We are also assuming that the two partners are indifferent between time spent in housework and time spent in market work. If we wished to allow for differential preferences over the two time uses then we would need to include $h_{A}$ in $A$ 's utility function, and similarly for $B$.

We extend preferences by allowing that each person cares for the other (or 'defers to' the other, to use a term suggested by Pollak) and that the respective social welfare functions for the household are given by:

$$
\begin{aligned}
& \Psi_{A}=u^{A}+\lambda_{A} u^{B} \\
& \Psi_{B}=u^{B}+\lambda_{B} u^{A}
\end{aligned}
$$

where we shall assume that the weights $\lambda_{A}$ and $\lambda_{B}$ are non-negative. Given these preferences there are a number of ways of modelling the interactions between the two partners that lead to household outcomes. Here we adopt a collective framework in which the two partners agree that they will maximise the weighted sum of their individual social welfare functions to generate a household social welfare function, $\Psi$, according to:

$$
\begin{aligned}
\Psi\left(x_{A}, x_{B}, Q, l_{A}, l_{B}\right) & =\tilde{\mu} \Psi_{A}+(1-\tilde{\mu}) \Psi_{B}, \tilde{\mu} \in[0,1] \\
& =\mu u^{A}\left(x_{A}, Q, l_{A}\right)+u^{B}\left(x_{B}, Q, l_{B}\right)
\end{aligned}
$$

where the second expression follows from a convenient re-normalisation, using (6) and (7). The Pareto weight $\mu$ is a composite of the distribution of power within the household (the parameter $\tilde{\mu}$ ) and the degree of caring (given by $\lambda_{A}$ and $\left.\lambda_{B}\right)$. This brings out explicitly that one person caring for the other has a similar effect for observables as a lack of power. If we assume that the Pareto weight for $A, \mu$, is a fixed constant then we have a 'unitary' model. As opposed to this, an important idea in the 'collective' framework is that the Pareto weight (which is here defined as the weight put on the woman's individual utility in the household utility function) is positively related to the 'power' of the wife. Generally, the intra-household distribution of 'power' may depend on so-called distribution factors. These are potential observables such as relative wages and extra-household factors such as the 
sex ratio in the population and unobservables such as the degree of caring and the personalities of the two partners.

Given the constraints (equations (1) to (4)) and (8) we have the following four equations (the derivations are given in the Appendix):

$$
\begin{gathered}
\frac{u_{x}^{B}}{u_{x}^{A}}=\mu \\
\frac{u_{l}^{B}}{u_{l}^{A}}=\mu \frac{w_{B}}{w_{A}}=\frac{\mu}{w} \\
\frac{u_{l}^{B}}{u_{x}^{B}}=w_{B} \\
\frac{u_{l}^{A}}{u_{x}^{A}}=w_{A}
\end{gathered}
$$

From (11) and (12) we see that each partner acts as an individual for their choice of private consumption and leisure, conditional on a given level of $Q$. This is the familiar result that if there are no externalities then we can decentralise any allocation by a redistribution of initial endowments. In this case it is as though, given $Q, A$ solves:

$$
\max _{x_{A}, l_{A}} u^{A}\left(x_{A}, Q, l_{A}\right) \text { subject to } x_{A}+w_{A} l_{A}=y_{A}
$$

where $y_{A}$ is $A$ 's allocation of income for private expenditure and leisure. The term $y_{A}$ is known as the sharing rule in the intra-household literature. Note that we have:

$$
y_{A}+y_{B}=\left(y-x_{H}\right)+\left(T-h_{A}\right) w_{A}+\left(T-h_{B}\right) w_{B}
$$

so that the individual notional incomes sum to full income for the household, net of the costs of inputs to the public good. In the analysis here where we explicitly consider time use, the sharing rule is for the sharing of full income; that is, both time and money (net of expenditures on the public good). Once we have empirical estimates of the utility and Pareto weight functions we shall present results for the sharing rule for full expenditures. 


\subsection{A convenient parameterisation}

In the following treatment of the model for the household equilibrium set out in equations (9) through (12), we focus on the first two of these conditions. These can be used to derive expressions for relative expenditure and relative leisure that we discussed in the introduction to this paper. This expression will generally contain the unobservable level of home produced good, $Q$, so that we have to assume some separability in the utility function in our empirical work. We choose to work with a particularly simple parameterisation that incorporates this assumption. As discussed in the introduction, this simple parameterisation allows us to derive key theoretical results and also to derive a tractable structural model to take to the data. The model also implies some over-identifying assumptions which we shall test. The value of having an explicit structural model for the empirical analysis is that it allows us to state our identifying assumptions clearly and it allows us to interpret the estimated parameters.

We assume that the utility functions are additive over the three arguments:

$$
\begin{aligned}
& u^{A}=\theta_{A} \ln \left(x_{A}\right)+\tau_{A}\left(\frac{\rho}{\rho-1}\right)\left(l_{A}\right)^{\left(\frac{\rho-1}{\rho}\right)}+f(Q) \\
& u^{B}=\theta_{B} \ln \left(x_{B}\right)+\tau_{B}\left(\frac{\rho}{\rho-1}\right)\left(l_{B}\right)^{\left(\frac{\rho-1}{\rho}\right)}+f(Q)
\end{aligned}
$$

where, without loss of generality, we have normalised the preferences on the public good to be the same for both partners. This parameterisation has two major restrictions: the additivity and the use of power forms for consumption and leisure. The additivity is restrictive, but not as much as might first be thought. For example, it is reasonably well established that consumption and market work are complementary (see Browning, Hansen and Heckman (1999) for a survey of empirical results). This is usually assumed to be because there are costs of going to work and because agents can substitute housework for market goods in household production. The additive forms given in (13) imply the observed non-separabilities of total expenditure and market work; details are given in the Appendix A.2. Thus the additive form is more flexible than it first appears.

The second restrictive feature of our parameterisation is the use of the power form. This is frankly for convenience since it allows us to derive closed form expressions for relative leisure and relative expenditure. If we took other 
forms then we would have four equations (for each partners level of leisure and expenditure) rather than two. The power form taken for the sub-utility function for leisure is to allow that labour supply in a unitary model may not be very responsive to changes in wages. Concavity requires $\rho>0$ and some leisure is always required if $\rho<1$. The parameter $\rho$ is the negative of the Frisch (or $\lambda$-constant) elasticity of leisure with respect to the wage; details are given in Appendix A.3. Reliable estimates of this parameter are in short supply (see Browning et al (1999)) but a low value (of about 0.1) is thought appropriate. ${ }^{6}$

Within household heterogeneity is captured by the parameters $\theta_{A}, \theta_{B}, \tau_{A}$ and $\tau_{B}$; we postpone discussion of between household heterogeneity until the next subsection. From (9) we have:

$$
\mu=\frac{u_{x}^{B}}{u_{x}^{A}}=\frac{\theta_{B}}{\theta_{A}} \frac{x_{A}}{x_{B}}=\left(\theta^{-1}\right) \frac{x_{A}}{x_{B}}
$$

where $\theta=\theta_{A} / \theta_{B}$ symbolizes A's preferences for private consumption relative to $B$ 's preferences for consumption. Denoting $A$ 's relative consumption by $x$ we have:

$$
x=\frac{x_{A}}{x_{B}}=\theta \mu
$$

The distribution of leisure in the household is given by (10). It is straightforward to show that $A$ 's relative leisure, $l$, is given by:

$$
l=\frac{l_{A}}{l_{B}}=\left(\mu \tau \frac{w_{B}}{w_{A}}\right)^{\rho}=(\mu \tau)^{\rho} w^{-\rho}
$$

where $\tau=\tau_{A} / \tau_{B}$ is $A^{\prime}$ 's relative weighting for leisure. ${ }^{7}$

We consider first comparative statics results for a unitary model. For variations in $(\mu, \theta, \tau)$ these are:

$$
\begin{aligned}
& \frac{\partial x}{\partial \mu}>0, \frac{\partial l}{\partial \mu}>0 \\
& \frac{\partial x}{\partial \theta}>0, \frac{\partial l}{\partial \theta}=0
\end{aligned}
$$

\footnotetext{
${ }^{6}$ We could replace the log for private consumption by a similar formulation, but this turns out not to be necessary in the empirical analysis.

${ }^{7}$ Note that if we allowed the curvature parameter $\sigma$ to vary across the partners then we would not have a simple form for the relative leisures.
} 


$$
\frac{\partial x}{\partial \tau}=0, \frac{\partial l}{\partial \tau}>0
$$

The first result states that $A$ 's consumption and leisure both increase if her Pareto weight increases. The other two pairs of equations show that we can sensibly interpret $\theta$ and $\tau$ as being pure consumption and leisure heterogeneity terms. More interesting is the effect of changes in distribution factors for a non-unitary model. We denote the distribution factors by $\left(z_{1}, \ldots z_{D}, w\right)$ where we distinguish between unspecified distribution factors (the $z_{d}$ 's) and the relative wage. We have (denoting the partial of $\mu$ with respect to $z_{d}$ by $\left.\mu_{d}\right)$ :

$$
\begin{aligned}
\frac{\partial x}{\partial z_{d}} & =\theta \mu_{d} \\
\frac{\partial l}{\partial z_{d}} & =\rho \mu^{\rho-1} \tau^{\rho} w^{-\rho} \mu_{d}
\end{aligned}
$$

and

$$
\begin{aligned}
\frac{\partial x}{\partial w} & =\theta \mu_{w} \\
\frac{\partial l}{\partial w} & =-\rho(\mu \tau)^{\rho} w^{-\rho-1}+\rho \mu^{\rho-1} \tau^{\rho} w^{-\rho} \mu_{w}
\end{aligned}
$$

Equations (20) to (23) have two interesting corollaries. The first considers the reactions to two different non-wage distribution factors, $z_{i}$ and $z_{j}$. Dividing one by the other we have the following proportionality result:

$$
\frac{\partial x}{\partial z_{i}} / \frac{\partial l}{\partial z_{i}}=\frac{\partial x}{\partial z_{j}} / \frac{\partial l}{\partial z_{j}}
$$

This extends the proportionality results of Browning et al (1994) and Bourguignon et al (2005) which derive similar restrictions for demands. Those papers show that these restrictions are necessary and sufficient for a collective model. The restriction (24) is testable if we have at least two distribution factors.

The second interesting implication of the responses to changes in distribution factors is the result for the variation of the relative leisure, $l$, with respect to the relative wage, equation (23). The first term on the right hand side is the familiar labour supply response which is the only effect in the unitary model. Here we shall call this effect the unitary effect. It is negative 
which implies that an increase in $A$ 's relative wage leads to a fall in her relative leisure. In a unitary setting the Pareto weight is unaffected by the change in relative wages $\left(\mu_{w}=0\right)$, so that she will be relatively worse off (as compared to her husband) even though her relative wage has increased. Of course, she may be absolutely better off since the total expenditure increases. If we assume that a higher relative wage increases the Pareto weight $\left(\mu_{w}>0\right)$ then the second expression on the right hand side of (23) is positive. This represents the collective effect, over and above the unitary effect. Formally the collective effect will dominate if the elasticity of the Pareto weight with respect to the relative wage is greater than unity:

$$
\frac{\partial l}{\partial w}>0 \Leftrightarrow \frac{\partial \ln \mu}{\partial \ln w}>1
$$

Once again, this is a testable condition. The relative expenditure response to a change in the relative wage (22) is positive if the Pareto weight is positively related to the relative wage $\left(\mu_{w}>0\right)$. In a unitary framework, relative expenditure is unaffected by a change in the relative wage $\left(\mu_{w}>0\right)$. This is also a testable condition.

\subsection{Heterogeneity}

In our empirical work we shall use a cross-section of Danish households. In this subsection we discuss informally how heterogeneity in the population relates to observables such as the distribution of private expenditures within the household. In our data we observe: $\left\{x_{A}, x_{B}, w_{A}, w_{B}, l_{A}, l_{B}, m_{A}, m_{B}, h_{A}, h_{B}\right\} .{ }^{8}$ We also observe demographics such as the age, education and work status of the partners, household composition (mainly the number and ages of children) and household income. In our empirical work below we shall concentrate on the female relative leisure, $l$, and household expenditure, $x$. In particular, we will investigate how these variables relate to observable characteristics and to each other through unobservables.

We begin our discussion assuming that we have a sample of households from a population who all have the same observable characteristics, including wages $w_{A}$ and $w_{B}$. In the model of the last subsection, equations (15) and

\footnotetext{
${ }^{8}$ Actually, we only observe three sub-components of expenditures for each partner on private goods; we postpone how we deal with the missing information until the empirical section.
} 
(16), we had three parameters for each household: $\{\mu, \theta, \tau\}$. These parameters are distributed across our population. Given particular assumptions on the joint distribution of household parameters, we ask what are the implications for the joint distribution of $\{x, l\}$ for the population? The important implications are the following.

Proposition 1 If there is variation in power across the population so that $\mu$ has a non-degenerate distribution and $\theta$ is independent of $\tau$ then $x$ and $l$ will be positively correlated.

This corresponds to the case in our introduction in which variations in expenditure and leisure shares derive from variations in the 'power' parameter $\mu$. The converse case is given by:

Proposition 2 If there is no variation in $\mu$ but $\theta$ and $\tau$ are negatively correlated then $x$ and $l$ will be negatively correlated.

That is, if the relative taste (between husband and wife) for leisure and the relative taste for private expenditure are negatively correlated then shares will also be negatively correlated. This corresponds to the 'taste difference' case discussed in the introduction. In general, of course, we must allow that all three factors are heterogeneous and interdependent.

Having considered unobserved heterogeneity we can now consider observable heterogeneity. In our sample, households differ widely in their observable characteristics and we have to allow that the household parameters depend on these. To accommodate this, we assume that the parameters depend on observables. In the case of the Pareto weight $\mu$, the dependence is on what are termed distribution factors as well as on unobservable factors. Candidates for the observable distribution factors are household income and the relative wages, relative ages and relative educational levels of the two partners. The unobservables could include, for example, the outside options the two partners have (contained in $\tilde{\mu}$ in equation (8)) and how much they care for each other $\left(\lambda_{A}\right.$ and $\lambda_{B}$ in (6) and (7)). The other two parameters, $\theta$ and $\tau$, are taste parameters that may depend on unobservables such as the idiosyncratic taste for work and an observable vector of preference factors such as the age and education of the two partners and the presence of children.

One weakness of our model is that we have assumed away complementaries between female and male time use. Previous contributions, using unitary models, by Hamermesh (2000), Hallberg (2003) and Ruuskanen (2004) 
address the issue of couples synchronising their time in both market work, housework and leisure and analyze the effects of economic and demographic variables on jointness in time-use. A central feature in these contributions is the distinction between a general time synchronization in society, due to the organisation of the labour market, shop opening hours etc., and the intended synchronization of couples' time based on their wish to spend some time together. This distinction is usually analyzed based on the difference between synchronization of time in 'pseudo couples' who have been matched based on a number of observable characteristics and in real couples, see Hallberg (2003). Based on Finnish time-use data with a highly detailed level of activities, Ruuskanen (2004) finds that couples tend to spend around 20\% - 25\% of their leisure together during weekdays, while around one third of the leisure is spent together during weekends. The overall conclusion in the contributions by Hamermesh (2000), Hallberg (2003) and Ruuskanen (2004) is that jointness in the timing of leisure and housework is important. However, the evidence regarding the sign and size of the effects of economic and demographic variables is somewhat mixed. Allowing for complementarity by extending the collective model we use leads to a much more complicated model and we leave it for future work. However, some simulations of our model suggest that introducing complementarity would not change the sign of the effects discussed above, but would only tend to diminish the numerical size of the effects since the two partners will tend to make their individual leisure choice approach the leisure approach of their partner.

\subsection{Empirical specification}

As mentioned above, in our empirical work, we concentrate on the female relative expenditure and leisure share, see equations (15) and (16). We have information on wages, $w_{A}$ and $w_{B}$, but we do not, of course, have any measures for $\mu, \theta$ and $\tau$. In the household allocation literature, it is usually suggested that the Pareto weight $\mu$ depends on a set of distribution factors including the differences in age, education and wage between the two spouses as well as environmental factors as the population (or regional) sex ratio. All these factors impact each of the spouses opportunities outside the marriage and are therefore argued to affect each of the partners 'power' within the marriage. For the empirical specification of the model, we model $\mu$ in the following way (re-calling that $w$ represents the relative wage): 


$$
\mu=\exp \left(\alpha_{0}+\alpha^{\prime} \mathbf{z}_{d}+\delta_{w} \ln (w)+\varepsilon_{\mu}\right)
$$

where $\mathbf{z}_{d}$ is a $D$-vector of non-wage distribution factors. ${ }^{9}$ The unitary effect outweighs the collective effect in equation (23) if $\delta_{w}<1$. The zero-mean variable $\varepsilon_{\mu}$ is an error term which captures other factors affecting $\mu$ which we have not been able to account for explicitly with our data.

Turning to the preference parameters, we model $A$ 's relative taste for consumption and leisure, $\theta$ and $\tau$ respectively, as a function of a set of household attributes such as age and the presence of children, $\mathbf{z}_{a}$, and unobservable components:

$$
\begin{aligned}
\theta & =\exp \left(\gamma_{\theta 0}+\gamma_{\theta}^{\prime} \mathbf{z}_{a}+\varepsilon_{\theta}\right) \\
\tau & =\exp \left(\gamma_{\tau 0}+\gamma_{\tau}^{\prime} \mathbf{z}_{a}+\varepsilon_{\tau}\right)
\end{aligned}
$$

We assume that the distribution factors $\left(\mathbf{z}_{d}, \ln (w)\right)$ are disjoint from the preference factors $\mathbf{z}_{a}$.

Before substituting these parameterisations into the equations derived above we have to take account of the fact that we only observe a subset of expenditures by each partner. If we let $x^{*}$ denote the 'true' relative expenditure and $x$ be the relative expenditure calculated from the subset of goods we observe then we define implicitly a factor $\eta$ by:

$$
x \equiv e^{\eta} x^{*}
$$

The factor $\eta$ varies across households. Our model above relates to $x *$ but our empirical modelling uses $x$.

Entering (26), (27) and (28) into (15) and (16) (allowing for equation (29)) and taking logs, we have the following pair of structural equations for the shares of observables:

$$
\ln \frac{x_{A}}{x_{B}}=\ln x=\left(\alpha_{0}+\gamma_{\theta 0}\right)+\alpha^{\prime} \mathbf{z}_{d}+\gamma_{\theta}^{\prime} \mathbf{z}_{a}+\delta_{w} \ln (w)+\left(\varepsilon_{\theta}+\varepsilon_{\mu}+\eta\right)
$$

\footnotetext{
${ }^{9}$ In our empirical work below we test for whether the two log wage measures enter separately (so that the Pareto weight depends on the level of wages as well as the relative value). We reject this so we discuss the simpler form here.
} 
and

$$
\begin{aligned}
\ln \frac{l_{A}}{l_{B}}= & \ln l=\rho\left(\alpha_{0}+\gamma_{\tau 0}\right)+\rho \alpha^{\prime} \mathbf{z}_{d}+\rho \gamma_{\tau}^{\prime} \mathbf{z}_{a} \\
& +\rho\left(\delta_{w}-1\right) \ln (w)+\rho\left(\varepsilon_{\tau}+\varepsilon_{\mu}\right)
\end{aligned}
$$

Our primary parameters of interest are the Pareto weight parameters $\left(\alpha_{0}, \alpha, \delta_{w}\right)$. This structural system has a system of linear reduced forms:

$$
\begin{aligned}
\ln x & =\pi_{x 0}+\pi_{x}^{\prime} \mathbf{z}_{d}+\pi_{\theta}^{\prime} \mathbf{z}_{a}+\pi_{x w} \ln (w)+\varepsilon_{x} \\
\ln l & =\pi_{l 0}+\pi_{l}^{\prime} \mathbf{z}_{d}+\pi_{\tau}^{\prime} \mathbf{z}_{a}+\pi_{l w} \ln (w)+\varepsilon_{l}
\end{aligned}
$$

Although parameter $\rho$ is identified if we have estimates of the reduced form parameters, we do not feel confident in the estimate since it is a parameter that governs intertemporal allocation and we have only cross-section data. Consequently we shall present results with a priori plausible values for $\rho$.

If we fix $\rho$ then all of the parameters of primary interest are identified from either equation, except for the intercept $\alpha_{0}$. The result that we cannot identify the 'location' of the Pareto weight is generic; as Bourguignon et al (2005) we can only identify the Pareto weight if we observe the allocation of all goods to each partner. If we take a particular value for $\rho$ then this gives the following $D+1$ cross-equation restrictions:

$$
\begin{aligned}
\pi_{l}^{i} & =\rho \pi_{x}^{i} \text { for } i=1,2 \ldots D \\
\pi_{l w} & =\rho\left(\pi_{x w}-1\right)
\end{aligned}
$$

where $\pi_{l}^{i}$ is the $i$ th element of $\pi_{l}$. These restrictions are a test of our maintained assumptions. Finally we note that if we assume that $\varepsilon_{\theta}, \varepsilon_{\tau}$ and $\eta$ are distributed independently of each other then we expect a positive correlation between the errors in the two reduced form equations, through their dependence on $\varepsilon_{\mu}$.

To close this section we consider the identification of our parameters of interest. Since we do not have panel data we necessarily have to make strong assumptions concerning the unobserved heterogeneity. The strongest assumption is that both the composite errors $\varepsilon_{x}$ and $\varepsilon_{l}$ are uncorrelated with the right hand side variables in the two equations. For some of the components this is unobjectionable. For example, the assumption that the mismatch between true expenditure shares and observed expenditure shares $(\eta)$ is uncorrelated with a preference factor such as age is probably innocuous. 
The strongest element of our identifying assumption is that wages are uncorrelated with $\varepsilon_{\tau}$ which captures relative preferences for work. We might well expect that a high taste for work leads to higher wages, all other observables (such as education) being considered. In the intrahousehold literature we are forced to make this exogeneity assumption for want of a decent instrument for wages. Since we have two equations and cross-equation restrictions, we can test for this in our framework. Suppose that:

$$
\varepsilon_{l}=\kappa \ln (w)+\tilde{\varepsilon}_{l}
$$

where $\tilde{\varepsilon}_{l}$ is uncorrelated with $\ln (w), \mathbf{z}_{d}$ and $\mathbf{z}_{a}$. Then the log relative wage in equation (33) is exogenous if and only if $\kappa=0$. Substituting (36) into (31) gives:

$$
\ln l=\ldots+\rho\left(\delta_{w}-1+\kappa\right) \ln (w)+\rho\left(\tilde{\varepsilon}_{\tau}+\varepsilon_{\mu}\right)
$$

In this case, the test for the restriction in (35) can be viewed as an exogeneity test. If we reject exogeneity then we only impose estimate (34) to derive our estimates of the structural parameters. Note, however, that the test depends on the value of $\rho$ we assume and we can always choose a value for the latter that makes the estimate of $\kappa$ exactly zero.

\section{Results}

\subsection{Parameter estimates and tests}

We first present the estimates for a completely unrestricted model, see Table 4. A number of features of these estimates deserve attention. First, the children variables are insignificant in both equations. It is important to emphasise that the latter finding for the leisure equation does not imply that mothers and fathers do the same amount of child care (here classified as housework); for example the estimates are consistent with mothers doing more child care and fathers doing more market work (a common finding in the literature for young children) or more other types of housework. Second, the parameter estimates for log wages in the expenditure equation are of very similar absolute magnitude but opposite sign (see the footnote following equation (26)). Third, the age variables in the two equations sum to close to zero and are significant in the expenditure equation. Fourth, the education variables enter with the same sign within each equation. 


\begin{tabular}{|l|c|c|c|c|}
\hline & \multicolumn{2}{|c|}{$\begin{array}{c}\text { Relative } \\
\text { expenditures }\end{array}$} & \multicolumn{2}{c|}{$\begin{array}{c}\text { Relative } \\
\text { leisures }\end{array}$} \\
\hline \hline Constant & -.735 & {$[1.20]$} & -.243 & {$[1.34]$} \\
\hline log gross hhold inc. & .183 & {$[1.04]$} & .096 & {$[1.83]$} \\
\hline log wife's wage & .195 & {$[1.95]$} & -.098 & {$[3.28]$} \\
\hline log husband's wage & -.192 & {$[1.62]$} & -.012 & {$[0.35]$} \\
\hline wife's age & -.019 & {$[3.24]$} & .000 & {$[0.01]$} \\
\hline husband's age & .015 & {$[2.59]$} & -.000 & {$[0.17]$} \\
\hline wife's education & -.012 & {$[1.07]$} & .006 & {$[1.90]$} \\
\hline husband's education & -.004 & {$[0.34]$} & .007 & {$[2.15]$} \\
\hline \# young children & -.059 & {$[1.09]$} & -.003 & {$[0.19]$} \\
\hline \# older children & -.015 & {$[0.30]$} & -.011 & {$[0.76]$} \\
\hline \hline$R^{2}$ & .027 & .039 \\
\hline Correlation $\left(\chi^{2}(1)\right)$ & \multicolumn{5}{|c|}{$0.11(6.92)$} \\
\hline \hline Values in [.] are absolute t-values. \\
\hline
\end{tabular}

Table 4: Estimates of unrestricted model

Before moving on to the structural estimation it is worth testing for some restrictions on the reduced form; specifically, whether we can replace the levels of his and her variables by their difference. More specifically, we test whether the coefficient to the wife's wage is equal to the negative of the coefficient to the husband's wage etc., as our first look at the estimates suggests. We test these restrictions on both equations jointly. The $\chi^{2}(2)$ statistics for these within-equation restrictions on the log wages, age and education are $4.69,2,33$ and 19.94 respectively (with probabilities of $9.6 \%, 31 \%$ and 0 respectively). ${ }^{10}$

Consequently we impose the first two restrictions on the reduced form; parameter estimates are given in Table 5. As can been seen, the coefficients on other variables do not change significantly and the differenced variables are more 'significant'. Thus the reduced form estimates point toward relative wage having a positive effect on the relative expenditures and a negative effect on relative leisures. The difference between her age and his age has a negative effect on relative expenditure implying that the oldest of the spouses has a relatively smaller expenditure share. Finally, note that the $R^{2}$ is low for both equations and that there is significant positive correlation between the errors

\footnotetext{
${ }^{10}$ In all cases the difference is her value minus his.
} 


\begin{tabular}{|l|c|c|c|c|}
\hline & \multicolumn{2}{|c|}{$\begin{array}{c}\text { Relative } \\
\text { Variable }\end{array}$} & \multicolumn{2}{c|}{$\begin{array}{c}\text { Relative } \\
\text { leisures }\end{array}$} \\
\hline \hline Constant & -.706 & {$[1.16]$} & -.227 & {$[1.24]$} \\
\hline Log gross hhold inc. & .146 & {$[1.40]$} & .003 & {$[0.09]$} \\
\hline Log relative wage & .191 & {$[2.83]$} & -.051 & {$[2.52]$} \\
\hline Relative age & -.016 & {$[2.93]$} & .001 & {$[0.36]$} \\
\hline Female education & -.011 & {$[0.96]$} & .006 & {$[1.82]$} \\
\hline Male education & -.003 & {$[0.26]$} & .007 & {$[2.12]$} \\
\hline Young children & -.021 & {$[0.44]$} & -.002 & {$[0.16]$} \\
\hline Older children & -.023 & {$[0.46]$} & -.010 & {$[0.73]$} \\
\hline$R^{2}$ & \multicolumn{3}{|c|}{027} & .039 \\
\hline Correlation $\left(\chi^{2}(1)\right)$ & \multicolumn{5}{|c|}{$0.11(6.97)$} \\
\hline Values in [.] are standard errors. \\
\hline
\end{tabular}

Table 5: Estimates of reduced form

in the two equations. We turn now to the interpretation given the structural model derived above.

\subsection{Structural estimates and implications}

When we consider the theoretical restrictions on the reduced form equation estimates we have to decide which right hand side variables are distribution factors and which are preference factors. For the former, relative wages and household gross income are natural candidates since they are not usually taken to be preference factors and hence should only enter the expenditure equation through the Pareto weight. Conversely, the children dummies can reasonably be taken as preference factors since they impact directly on the value of leisure. Following the results in Browning et al (1994)) we also choose to take the difference in age as a distribution factor; this does not rule out that preferences depend on age but simply that the dependence is the same for husband and wife. We leave the classification of the education variables to the data. If we do not impose exogeneity of the relative wage in the leisure equation (see equation (37)) then we have two restrictions (for the difference in age and log household income). To test we take a value for the curvature parameter of $\rho=0.1$, which is in line with $\rho$-values found in other 
empirical studies. ${ }^{11}$ The value of the $\chi^{2}(2)$ test statistic for the restriction given in equation $(34)$ is 1.81 (probability $=40 \%$ ). We impose these two restrictions and then test for (35). Given that we assume that relative wage is a distribution factor, this is a test for the exogeneity of log relative wages in the relative leisure equation. The $\chi^{2}(1)$ statistic for exogeneity is 2.69 (probability $=10 \%$ ). Given that this is marginally significant we shall present results with and without exogeneity. The first and second set of columns in Table 6 present the estimates for the structural model without and with (35) imposed respectively. ${ }^{12}$

Our main parameter of interest is the coefficient for the log relative wage. As we would expect the effect is stronger when we impose exogeneity (compare the estimates of 0.189 and 0.213 in the expenditure equation) but for both cases it is positive in the consumption equation and negative in the relative leisure share equation. As we recall from (22), the relative wage only affects relative expenditure through its positive effect on the Pareto weight, see equations (25) and (31). This is evidence in favour of the collective model. The fact that the relative wage is negative in the relative leisure equation is not contradictory to the collective framework, but on the other hand a positive effect would have given extra evidence in its support. However, a negative effect means that the unitary effect outweights the collective effect for leisures, see (23).The difference in age has a negative effect on the Pareto weight so that wives who are older than their husbands have less power. Finally, the level of gross household income has a positive effect suggesting that wives do better in high income households but note that this effect is statistically weak. We interpret our results as being consistent with a nonunitary, collective framework as a suitable description of household decision making for expenditures and time use.

Figure 4 shows the implications of our estimates in graphical form, with exogeneity of relative wages imposed. Since the intercept for the Pareto weight is not identified (see the discussion preceding (34)) we take the relative expenditures to be unity when the wages and the ages are the same and household income is at the mean of the data. The variation in relative wages

\footnotetext{
${ }^{11}$ In our estimation the optimal value of $\sigma$ was 0.06 . Using this value rather than the value of 0.1 gives very similar results.

${ }^{12}$ The parameter estimates for the education variables suggest that we cannot treat them (or their difference) as distribution factors; a formal test of (34) confirms this. We also note that excluding the 'insignificant' preference factors makes only a small difference for the coefficients on the distribution factors.
} 


\begin{tabular}{|l|c|c|c|c|}
\hline \hline & Relative wage & Relative wage \\
\hline \hline \multicolumn{4}{|c|}{ endogenous } & exogenous \\
\hline \hline \multicolumn{4}{|c|}{ Relative expenditure equation } \\
Constant & -.657 & {$[1.10]$} & -.652 & {$[1.09]$} \\
Log hhold gross inc. & .138 & {$[1.35]$} & .138 & {$[1.35]$} \\
Log relative wage & .189 & {$[2.81]$} & .213 & {$[3.24]$} \\
Difference in age & -.015 & {$[2.71]$} & -.015 & {$[2.71]$} \\
Female education & -.010 & {$[0.94]$} & -.011 & {$[1.01]$} \\
Male education & -.003 & {$[0.23]$} & -.002 & {$[0.16]$} \\
Young children & -.021 & {$[0.44]$} & -.020 & {$[0.41]$} \\
Older children & -.022 & {$[0.44]$} & -.021 & {$[0.42]$} \\
\hline \hline \multicolumn{4}{|c|}{ Relative leisure equation } \\
Constant & -.289 & {$[4.01]$} & -.295 & {$[4.09]$} \\
Log hhold gross inc. & .014 & {$[1.35]$} & .014 & {$[1.35]$} \\
Log relative wage & -.048 & {$[2.47]$} & -.079 & {$[11.96]$} \\
Difference in age & -.001 & {$[2.71]$} & -.001 & {$[2.71]$} \\
Female education & .006 & {$[1.74]$} & .007 & {$[2.08]$} \\
Male education & .007 & {$[2.05]$} & .006 & {$[1.77]$} \\
Young children & -.002 & {$[0.15]$} & -.004 & {$[0.29]$} \\
Older children & -.012 & {$[0.81]$} & -.013 & {$[0.90]$} \\
\hline \hline Correlation of errors & \multicolumn{2}{|c|}{0.11} & \multicolumn{3}{|c|}{0.11} \\
\hline \hline Values in [.] are absolute t-values. \\
\hline
\end{tabular}

Table 6: Structural form estimates 


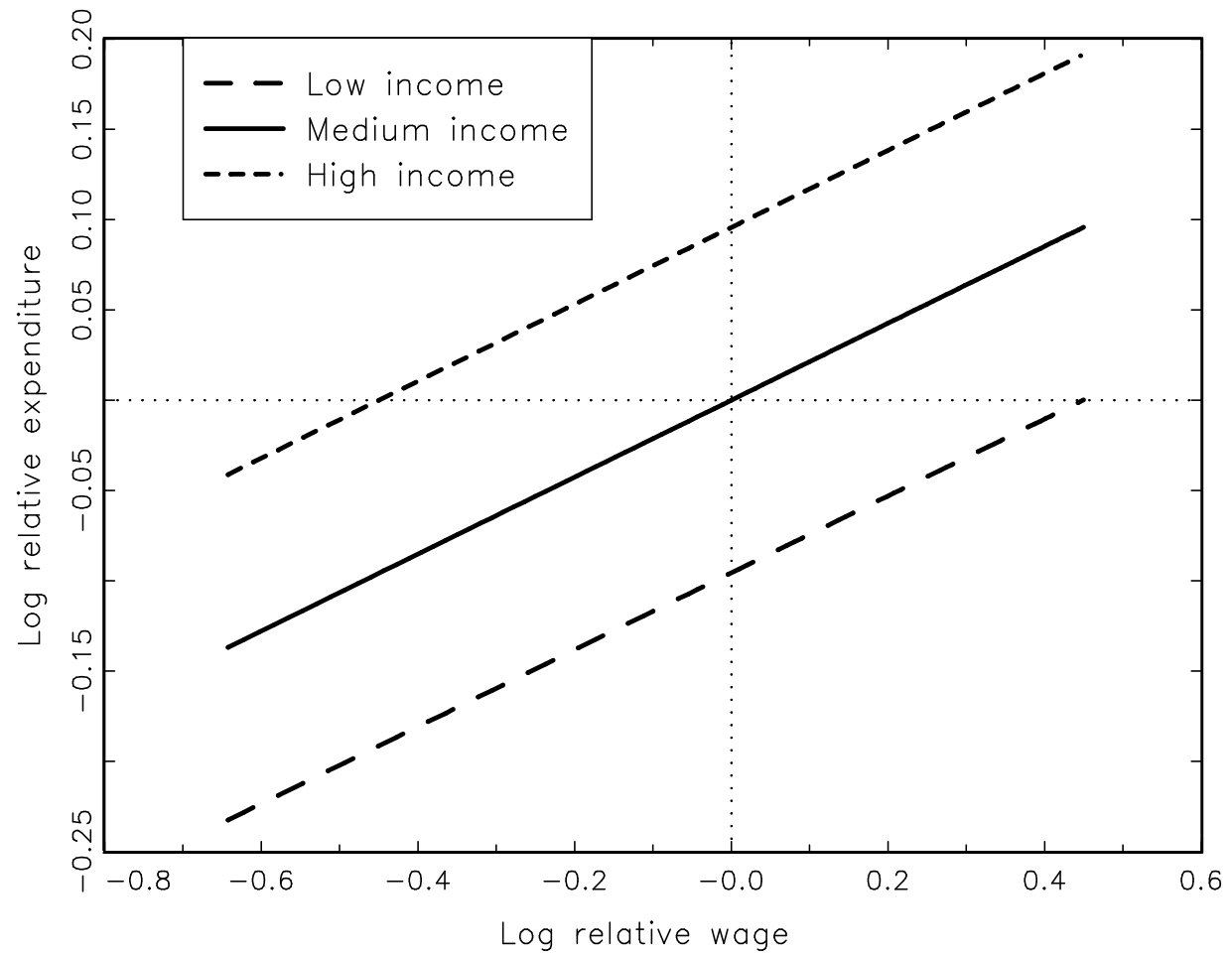

Figure 4: The variation in relative expenditures.

on the $\mathrm{x}$-axis is from her wage being half of his $(\ln w=-0.65)$ to her wage being $60 \%$ higher than his $(\ln w=0.5)$. The variation in relative expenditures over this range for medium income households is from around 0.86 to 1.11 so that changes in relative wages lead to substantial changes in expenditure shares: an elasticity of 0.22 . The upper and lower lines show the responses for changes in household income of one half of the mean to twice the mean; these are also substantial (about 0.89 to 1.09 ) but recall that these are imprecisely estimated. The results for the effect of relative wages on relative leisures are a compound of a unitary effect (here fixed to be 0.1 ) and a collective effect. For the latter the coefficients are the same as for relative expenditures except that the coefficient is multiplied by $\rho=0.1$ (see (30) and (31)). The unitary effect elasticity is -0.1 (by assumption) and the collective effect elasticity is +0.02 so that the net elasticity is 0.08 .

As we have seen the fits of our reduced form equations are rather poor 
( $2.7 \%$ and $3.9 \%$ for expenditures and leisures respectively) and most of the variation in relative expenditures and leisures is unexplained. If we are willing to make strong assumptions concerning the error terms in (30) and (31) then we can decompose this latent variation into that part which is due to the unobserved variation in Pareto weights and the part due to measurement error and unobserved preference factors. To do this we assume:

$$
E\left(\left(\varepsilon_{\theta}+\eta\right) \varepsilon_{\mu}\right)=E\left(\varepsilon_{\tau} \varepsilon_{\mu}\right)=E\left(\left(\varepsilon_{\theta}+\eta\right) \varepsilon_{\tau}\right)=0
$$

Under these assumptions the variances of $\left(\varepsilon_{\theta}+\eta\right), \varepsilon_{\tau}$ and $\varepsilon_{\mu}$ are identified from the error variances $\sigma_{x}^{2}$, and $\sigma_{l}^{2}$ and the covariance, $\operatorname{cov}\left(\varepsilon_{x}, \varepsilon_{l}\right)$. The estimated values of the latter are $0.329,0.0296$ and 0.01 respectively. Under our assumptions we have:

$$
\operatorname{cov}\left(\varepsilon_{x}, \varepsilon_{l}\right)=\rho \sigma_{\mu}^{2}
$$

so that the variance of $\varepsilon_{\mu}, \sigma_{\mu}^{2}$, is 0.1 . The proportions of the latent variation that are explained by the Pareto weight are given by:

$$
\begin{aligned}
\frac{\sigma_{\mu}^{2}}{\sigma_{x}^{2}} & =\frac{0.1}{0.329}=0.304 \\
\frac{\rho^{2} \sigma_{\mu}^{2}}{\sigma_{l}^{2}} & =\frac{0.01 * 0.1}{0.0296}=0.003
\end{aligned}
$$

for expenditures and leisures respectively. Thus about $30 \%$ of the unexplained variation in relative expenditures can be attributed to variations in power but only a fraction $(0.3 \%)$ can be attributed thus for the leisure relatives.

\section{Conclusions}

This paper treats the interactions between the allocation of time and the allocation of expenditure within the household. We develop a simple collective model with household production which allows us to bring out the main theoretical issues and also to discuss explicitly issues of accounting for heterogeneity, measurement error and exogeneity in our empirical work. We show that if there is no wage variation across households and there is heterogeneity in power and uncorrelated heterogeneity in preferences over work and 
private goods then relative expenditures and relative leisure will be positively correlated. Conversely, if there is no variation in power and preferences for work and private consumption are negatively correlated then the relative expenditures and leisures will be negatively correlated. We show how variations in wages across couples modify these predictions. For our parametrisation, the effects of changes in relative wages can be decomposed additively into a unitary effect and a collective effect. In the relative expenditure equation, the unitary effect is zero, so only the collective effect is in play. In the relative leisure equations, both effects are operating, see (23). These two effects have opposite signs so that the net effect is ambiguous. Finally, we provide a general proportionality test for a collective model in which all outcomes are efficient.

Although we present theoretical results, the main contribution of our paper is to provide an empirical analysis of the intra-household allocation of time and money, making use of a unique data set with information on both time use, assignable private expenditures and individual wages for more than 600 households. Even though we have a relatively small sample and noisy data some strong signals come through loud and clear in the empirical analysis. In the raw data, leisure and assignable expenditures are relatively equal for husbands and wives in the mean, but there is a great deal of heterogeneity across couples. We find that wives who have more leisure also have higher expenditures, without controlling for any observable covariates. In a reduced form analysis we find that relative wages have a significant and positive effect on relative expenditures and a significant and negative effect on relative leisures.

Turning to our structural model, we find that tests for a collective model do not reject. We also find that age differences and gross household income can be treated as distribution factors. The evidence on the exogeneity of relative wages in the relative leisure equation is marginal but the conclusions are much the same whether or not we treat relative wages as exogenous in that equation. In terms of observables, distribution factors have a large impact on relative expenditures but only a small (albeit, statistically significant) impact on relative leisures. Thus moving from the wife having a wage that is half her husband's to having a wage that is double increases her share of assignable expenditures by about $25 \%$. The same variation decreases her relative share of leisure by about $8 \%$, most of which can be attributed to the unitary effect. Most of the variation in observed relative expenditures and observed relative leisures is unexplained. Under strong assumptions we conclude that about 
$30 \%$ of the unexplained variation in relative expenditures is due to variations in unobserved power but almost none of the unexplained variation in leisures can be accounted for by variations in power.

\section{A Appendix}

\section{A.1 Derivation of theoretical results}

Given the household utility function:

$$
\begin{gathered}
\Psi=\mu u^{A}\left(x_{A}, Q, l_{A}\right)+u^{B}\left(x_{B}, Q, l_{B}\right)= \\
=\mu u^{A}\left(x_{A}, F\left(T-l_{A}-m_{A}, T-l_{B}-\frac{\left(x_{H}+x_{A}+x_{B}-y-w_{A} m_{A}\right)}{w_{B}}, x_{H}\right), l_{A}\right)+ \\
+u^{B}\left(x_{B}, F\left(T-l_{A}-m_{A}, T-l_{B}-\frac{\left(x_{H}+x_{A}+x_{B}-y-w_{A} m_{A}\right)}{w_{B}}, x_{H}\right), l_{B}\right)
\end{gathered}
$$

which is maximised with respect to the six control variables $\left(x_{A}, x_{B}, l_{A}, l_{B}, m_{A}, x_{H}\right)$. Assuming interior solutions ${ }^{13}$ we have the following first order conditions:

$$
\begin{gathered}
\mu u_{x}^{A}=\left(\mu u_{Q}^{A}+u_{Q}^{B}\right) \frac{F_{B}}{w_{B}} \\
u_{x}^{B}=\left(\mu u_{Q}^{A}+u_{Q}^{B}\right) \frac{F_{B}}{w_{B}} \\
F_{A}=\frac{\mu u_{l}^{A}}{\mu u_{Q}^{A}+u_{Q}^{B}} \\
F_{B}=\frac{u_{l}^{B}}{\mu u_{Q}^{A}+u_{Q}^{B}} \\
F_{A}=F_{B} \frac{w_{A}}{w_{B}} \\
F_{x}=F_{B} \frac{1}{w_{B}}
\end{gathered}
$$

\footnotetext{
${ }^{13}$ In our sample below, all partners are in market work and all report positive levels of leisure.
} 
In our data, we do not observe anything about the output of the public good produced, so we cannot hope to use the conditions on the marginal productivities $F_{A}, F_{B}$ and $F_{x}$. Rearranging the first-order conditions, we end up with the four equations (9)-(12) in the text.

\section{A.2 Derived preferences over total expenditure and market work}

We here show that if preferences over consumption, leisure and the home produced good are additive then derived preferences over total expenditure and market work have 'consumption' non-separable from market work. Suppose we have a single person with the utility function $u(x, Q, l)$ and access to home production $Q=F(h, y)$ where $h$ is housework and $y$ is expenditure on home production. Time use satisfies the constraint: $m+l+h=T$. We define a derived utility function over total expenditure, $c=x+y$, and market work, $m$, by:

$$
V(c, m)=\max _{y, h}\{u(c-y, F(h, y), T-h-m)\}
$$

That is, the total expenditure, $c$, is divided optimally between direct consumption $(c-y)$ and home production $(y)$ and housework is chosen optimally, given the market work level, $m$. By the envelope theorem we have:

$$
V_{c}(c, m)=u_{x}(c-\hat{y}, F(\hat{h}, \hat{y}), T-\hat{h}-m)
$$

where subscripts denote partial derivatives. Taking derivatives with respect to $m$ we have:

$$
V_{c m}(c, m)=-u_{x x} \frac{\partial \hat{y}}{\partial m}+u_{x Q}\left[F_{h} \frac{\partial \hat{h}}{\partial m}+F_{y} \frac{\partial \hat{y}}{\partial m}\right]-u_{x l} \frac{\partial \hat{h}}{\partial m}
$$

If we impose additivity on $u($.$) this gives:$

$$
V_{c m}(c, m)=-u_{x x} \frac{\partial \hat{y}}{\partial m}
$$

which is positive if housework and market inputs to home production are

substitutes $\left(\frac{\partial \hat{y}}{\partial m}<0\right)$. Thus consumption $(c)$ and market work $(m)$ are complements in the derived utility function. 


\section{A.3 The interpretation of the leisure curvature para- meter}

Once again we consider a single agent and we ignore home production. Our parameterisation (13) has:

$$
u(c, l)=\ln c+\left(\frac{\rho}{\rho-1}\right)(l)^{\left(\frac{\rho-1}{\rho}\right)}
$$

Denoting wage by $w$ the first order condition is:

$$
u_{l}=w u_{c}=\lambda w
$$

where $\lambda$ is the marginal utility of consumption. Using the parameterisation and normalising the total time available to unity $(l+h=1)$, we have the following closed form for the Frisch (or $\lambda$-constant) labour supply function:

$$
\hat{h}=1-(\lambda w)^{-\rho}
$$

The Frisch elasticity is then given by:

$$
\frac{\partial \hat{h}}{\partial w} \frac{w}{\hat{h}}=\rho\left(\frac{1-h}{h}\right) \simeq 2 \rho
$$

if we assume that full-time work is about $h=1 / 3$. Generally the left hand side elasticity is thought to be small with values of $0.1-0.2$ thought to be plausible, so that values of around $0.05-0.1$ are probably reasonable for $\rho$.

\section{A.4 Data selection}

The initial data set consists of 1767 couples. Of these couples, we have information on hours spent in the labour market, in household production and in leisure for 1522 couples. In our analysis we confine ourselves to looking at couples where both work full time, that is 813 couples. For a little more than 100 of these, we have no information on wage rates for both spouses in the household. We also have to have information on assignable consumption on clothing, recreation and other personal consumption for both partners in the household. For a good 50 of the couples, this information has not been given in the questionnaire. Finally, we drop a small number of outliers and end up with the data set used for this analysis of 615 couples. 


\section{A.5 Summary statistics}

In the table below are shown the summary statistics for the 615 couples used in the estimations.

\begin{tabular}{|l|c|c|c|c|}
\hline & Mean & Std. & Min. & Max. \\
\hline Female relative consumption & 1.20 & 0.72 & 0.09 & 4.70 \\
\hline Female relative leisure & 0.99 & 0.18 & 0.48 & 1.98 \\
\hline Female relative age & 0.96 & 0.10 & 0.64 & 1.53 \\
\hline Relative wage & 0.93 & 0.25 & 0.06 & 1.93 \\
\hline Household gross income & 0.61 & 0.20 & 0.15 & 2.72 \\
\hline Female age & 40.47 & 9.53 & 19 & 61 \\
\hline Female education, \# of years & 13.37 & 2.55 & 10 & 18 \\
\hline Dummy for young children (up to 6 years) & 0.39 & 0.49 & 0 & 1 \\
\hline Dummy for older children (7-17 years) & 0.31 & 0.46 & 0 & 1 \\
\hline
\end{tabular}

\section{A.6 Diary and survey time use}

Figure A.6 below compares the distributions of women's housework share (her housework relative to total housework) from the question on usual time use for housework and the information from the time diaries. As we would expect, the diary information is much more dispersed. This reflects infrequency in the diary information and rounding in the survey response data. This can be seen most clearly in the spikes at zero and unity. The means and medians of the two sources are $(0.61,0.60)$ for the diary and $(0.59,0.57)$ for the usual time response.

\section{References}

[1] Apps, P. (2003): Gender, Time Use and Models of the Household, IZA DP No. 796. IZA, Bonn.

[2] Apps. P., and R. Rees (1997): Collective Labour Supply and Household Production. Journal of Political Economy, Volume 105, Issue 1 (Feb., 1997), pp. 178-190.

[3] Apps. P., and R. Rees (1996): Labour Supply, household production and intra-family welfare distribution. Journal of Public Economics, 60, pp. 199-219. 

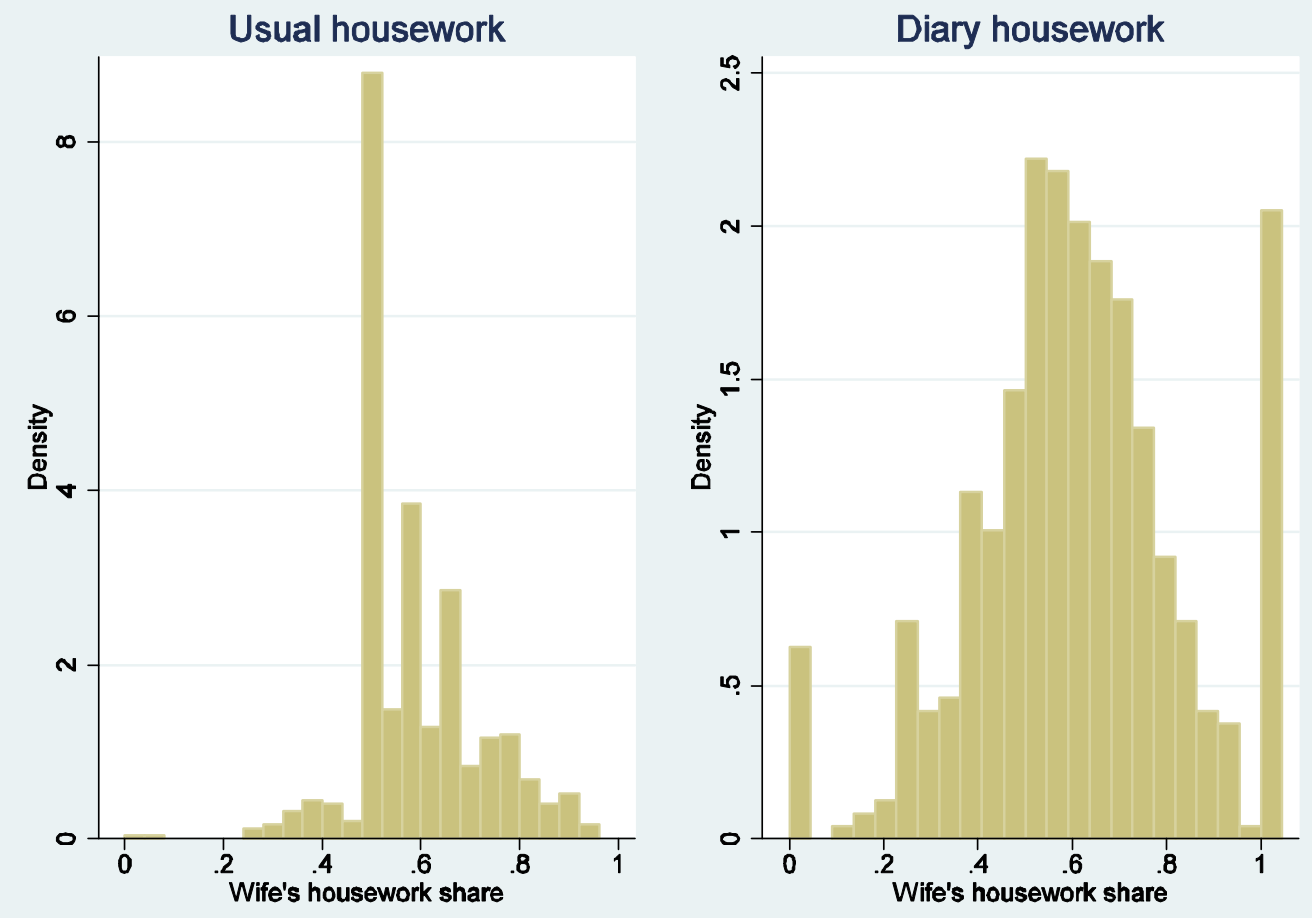
[4] Apps, P., and R. Rees (1988): Taxation and the household, Journal of Public Economics, Vol. 35, No. 3, April 1988, pp. 355-369.

[5] Aronsson, T., S.-O. Daunfeldt and M. Wikström (2001): Estimating intrahousehold allocation in a collective model with household production, Journal of Population Economics, 14, pp. 569-584.

[6] Becker, G. S. (1994): A Treatise on the Family. Cambridge, Mass. Harvard University Press. Cambridge, Massachusetts. London, England.

[7] Becker, G. S. (1965): A Theory of the Allocation of Time. Economic Journal, Vol. 75, No. 299 (Sep., 1965), pp. 493-517.

[8] Bonke, J. (2005): Paid and unpaid work - diary information versus questionnaire information. Social Indicator Research, Vol. 70, pp. 349368.

[9] Bourguignon, F., M. Browning and P.-A. Chiappori (2005): "Efficient intra-household allocations and distribution factors: implications and identification", mimeo, University of Copenhagen.

[10] Browning, M., P.-A. Chiappori and V. Lechene (2005), "Distributional effects in household models: separate spheres and income pooling", CAM Working Paper 2005-09, University of Copenhagen.

[11] Browning, M., L.P. Hansen and J. Heckman (1999), Micro Data and General Equilibrium Models, Handbook of Macroeconomics, Volume 1A, edited by J. Taylor and M. Woodford, North Holland, Amsterdam.

[12] Browning, M., F. Bourguignon; P.-A. Chiappori and V. Lechene (1994), "Income and outcomes: a structural model of intrahousehold allocation", Journal of Political Economy, 102(6), pp. 1067-96.

[13] Browning, M., and P.-A. Chiappori, (1998), "Efficient Intra-household Allocation: A General Characterisation and Empirical Tests", Econometrica, Vol. 66, No. 6, pp. 1241-78.

[14] Browning, M., T.F. Crossley and G. Weber (2003): Asking Consumption Questions in General Purpose Surveys. Economic Journal, Vol. 113, Issue 491, pp. 540-567. 
[15] Chiappori, P.-A. (1997): Introducing Household Production in Collective Models of Labor Supply. Journal of Political Economy, Volume 105, Issue 1 (Feb., 1997), pp. 191-209.

[16] Chiappori, P.-A. (1992): Collective Labour Supply and Welfare. Journal of Political Economy, Volume 100, Issue 3 (Jun., 1992), pp. 493-467.

[17] Chiappori, P.-A. (1988): Rational Household Labor Supply. Econometrica, Vol. 56, No. 1, January 1988, pp. 63-90.

[18] Hamermesh, D. (2000): Togetherness: Spouses' Synchronous Leisure and the Impact of Children. NBER Working Paper, No. 7455. Cambridge, USA.

[19] Hallberg, D. and A. Klevmarken (2003): Time for children: A study of parent's time allocation. Journal of Population Economics, Vol. 16, pp. 205-226.

[20] Juster, F.T. and F.P. Stafford (1991): The Allocation of Time: Empirical Findings, Behavourial Models, and Problems of Measurement. Journal of Economic Literature, Volume 29, Issue 2 ( June, 1991), pp. 471-522.

[21] Kerkhofs, M. and P. Kooreman (2003): Identification and Estimation of Household Production Models. Journal of Applied Econometrics, 18, pp. 337-369.

[22] Lundberg, S.J., R.A. Pollak and T.J. Wales (1996): Do Husbands and Wives Pool Their Resources? Evidence from the United Kingdom Child Benefit. Journal of Human Resources. XXXII-3.

[23] Phipps, S., and P. Burton (1998), "What's mine is yours? The influence of male and female incomes on patterns of household expenditure", Economica, Vol. 65, No. 260, pp. 599-613.

[24] Ruuskanen, O.-P. (2004): An Economic Analysis of Time Use in Finnish Households. Ph.D.-thesis. Helsinki School of Economics. HeSE. 